\title{
Fenhexamid - an efficient and inexpensive fungicide for selection of Magnaporthe oryzae transformants
}

\author{
Alex Wegner (D) Louisa Wirtz (D). \\ Thomas Leisen (1). Matthias Hahn (1). \\ Ulrich Schaffrath
}

Accepted: 23 November 2021 / Published online: 1 December 2021

(C) The Author(s) 2021

\begin{abstract}
Magnaporthe oryzae is one of the most economically important phytopathogenic fungi, and is used as a model organism to study plant-pathogen interactions. To unravel the infection process, forward and reverse genetic approaches are essential, but are often hindered by the lack of a straightforward selection procedure for transformants. Here we report on the use of fenhexamid, an inhibitor of ergosterol biosynthesis, for selection of $M$. oryzae transformants. An allele of the sterol 3-ketoreductase gene of Fusarium fujikuroi (FfERG27), known to confer resistance to fenhexamid, has already been used successfully with transformants of Botrytis cinerea. Our results demonstrate that expression of the FfERG27 allele in $M$. oryzae also enables highly efficient selection of transformants on fenhexamid-containing media. The use of fenhexamid is an inexpensive alternative for selection as compared to commonly used antibiotics like hygromycin. No impact on growth and infection phenotypes of fenhexamid resistant $M$. oryzae
\end{abstract}

Supplementary Information The online version contains supplementary material available at https://doi. org/10.1007/s10658-021-02432-3.

A. Wegner $\cdot$ L. Wirtz $\cdot$ U. Schaffrath $(\bowtie)$

Department of Plant Physiology, RWTH Aachen

University, 52056 Aachen, Germany

e-mail: schaffrath@bio3.rwth-aachen.de

T. Leisen - M. Hahn

Department of Biology, University of Kaiserslautern,

Kaiserslautern, Germany mutants was detected, which underpins its usefulness for selecting $M$. oryzae transformants.

Keywords Magnaporthe oryzae fenhexamid . $E R G 27 \cdot$ sterol 3-ketoreductase $\cdot$ selection $\cdot$ resistance marker

\section{Introduction}

The ascomycete $M$. oryzae, best known as the causal agent of rice blast disease, has become a major thread not only for rice but also for wheat cultivation (Martinez et al., 2021; Portz et al., 2021). For functional genetic analyses, selection markers are necessary to identify respective mutants. However, for $M$. ory$z a e$, only a few markers are well-established which e.g. limits the option of multiple gene deletions. For example, hygromycin is commonly used but a drawback is its high price and the relative high amount ( 0.2 to $0.6 \mathrm{mg} \mathrm{ml}^{-1}$ ) needed for selection of $M$. oryzae transformants (Jeong et al., 2007; Leung et al., 1990; Zhang et al., 2019). Alternatives for selection based e.g. on the use of glufosinate, benomyl or carboxin have rarely been reported (Guo et al., 2016; Jacob et al., 2015; Kachroo et al., 1997).

Here, we report on the use of fenhexamid resistance conferred by the gene FfERG27 of Fusarium fujikuroi to select transgenic $M$. oryzae mutants as described previously for Botrytis cinerea (Cohrs et al., 2017). Fenhexamid 
( $N$-(2,3-Dichlor-4-hydroxyphenyl)-1-methylcyclohexancarboxamid), marketed by Bayer CropScience as Teldor ${ }^{\circledR}$, is a fungicide effective against $B$. cinerea, Sclerotinia sclerotiorum and Monilinia spp. (Cohrs et al., 2017; Billard et al., 2011; Debieu et al., 2013). Fenhexamid inhibits the biosynthesis of sterols and belongs to the chemical family of hydroxyanilides (Billard et al., 2011; Debieu et al., 2001). Sterols, especially ergosterols, are known to be important for membrane integrity in fungi. Fenhexamid inhibits the C4-demethylation of ergosterol by blocking the sterol 3-ketoreductase, a conserved enzyme present in all euascomycetes (Billard et al., 2011; Debieu et al., 2001). Due to intensive use of the fungicide, fenhexamid resistant $B$. cinerea isolates have been observed in the field (Billard et al., 2011; Grabke et al., 2013). The fenhexamid resistance was associated with changes in the amino acid sequence of the sterol 3-ketoreductase at position 412 and two other amino acid positions that have a slightly less impact on fungicide resistance (Billard et al., 2011; Fillinger et al., 2008). Also for F. fujikuroi a field isolates (IMI 58289) was identified with an allele of the ERG27 gene (FfERG27) that mediates resistance against fenhexamid and which was used for selection of $B$. cinerea transformants (Cohrs et al., 2017). Using this knowledge, we broaden the tool box for M. oryzae by establishing fenhexamid as an effective and cost-efficient selection marker in transformation.

\section{Experimental procedures}

Fungal cultivation

The fungus was cultivated on complete medium (Talbot et al., 1993) or potato dextrose agar (PDA; Sigma Aldrich St. Louis, USA) at $23-25{ }^{\circ} \mathrm{C}$ in the dark.

Sporulation and inoculation

For sporulation a piece of mycelium was transferred to oatmeal agar (20 $\mathrm{g} \mathrm{l}^{-1}$ agar, $2 \mathrm{~g} \mathrm{l}^{-1}$ yeast extract, 10 $\mathrm{g} \mathrm{l}^{-1}$ starch, $30 \mathrm{~g} \mathrm{l}^{-1}$ oat flakes) and incubated at $26^{\circ} \mathrm{C}$ under fluorescent tubes (36W/840, Osram, Germany) mixed with blacklight tubes (TLD 36W/08 BLB UV, Phillips, Netherlands) for seven to fourteen days. Conidia were washed from agar plates in $\mathrm{ddH}_{2} \mathrm{O}$ and filtered through three layers of gauze. For inoculation of barley plants, concentration of conidia was adjusted to 40000 conidia $\mathrm{ml}^{-1}$ and diluted $1: 1$ with a solution containing $1 \mathrm{~g} \mathrm{l}^{-1}$ gelatin and $0.5 \mathrm{ml} \mathrm{l}^{-1}$ Tween 20. The suspension was sprayed onto sevenday-old primary leaves of barley $c v$. Ingrid and plants were cultivated in a growth chamber as described in Delventhal et al. (2014). Seven days post inoculation, leaves were harvested, placed on water agar plates and photographed using a Panasonic DMC-TZ61 camera. To determine disease severity, the infected part of each leaf was calculated in relation to the total leaf area using the image software Assess 2.0 (Image analysis software for plant disease quantification 2.0, https://my.apsnet.org/ItemDetail?iProductCode= 43696). To analyze the infection structures in vitro, $10 \mu \mathrm{l}$ of a spore suspension were placed on a glass slides and examined by microscopy after 14 or 24 hours.

Blast-analysis, alignments and database search

NCBI protein blast was used to obtain protein sequences form public depositories (https://blast. ncbi.nlm.nih.gov/Blast. cgi?PAGE= Proteins). Sequences were aligned using Jalview and Muscle with default settings (http://www.jalview.org/). Genomic sequences of strain 70-15 were obtained from NCBI database (https://www.ncbi.nlm.nih. gov/) and sequences of other Magnaporthe isolates were obtained from GEMO (http://genome. jouy.inra.fr/gemo/). Sequences of the ERG27 gene of the M. oryzae isolates CM28, PH14 and INA72 were analyzed after amplification by PCR using Phusion DNA polymerase (Thermo Fisher Scientific, Waltham, Massachusetts, USA) with primers MoErg27_F and MoErg27_R (Table S1). PCR products were sequenced by Microsynth Seqlab, Göttingen, Germany.

Generation of MoALB1 deletion mutants and $\mathrm{Fen}^{\mathrm{R}}$ mutants

Generation of $M$. oryzae Guy11 protoplasts was done by glucanex treatment as described by Leisen et al. (2020). The donor template, containing the $\mathrm{Fen}^{R}$ cassette (PtrpC, FfERG27, TniaD), was amplified with Phusion DNA polymerase (Thermo Fisher Scientific, Waltham, Massachusetts, USA) with primers MoAlb1MH_F and R (Table S1) and pTEL-Fen 
as template (Leisen et al., 2020). A 50 bp overhang, homologous to sequences at the MoALB1 locus, was added to primer sequences to enable homologous recombination similar to the procedure described by Foster et al. (2018). The PCR product was purified with a PCR-clean-up kit (NucleoSpin ${ }^{\mathrm{TM}} \mathrm{Gel}$ and PCR Clean-up Kit, Macherey-Nagel, Dueren, Germany) and solved in Tris- $\mathrm{CaCl}_{2}$ buffer (10 mM Tris-HCl, 1 mM EDTA, $40 \mathrm{mM} \mathrm{CaCl}_{2}, \mathrm{pH}$ 6.3) at a final concentration of $1 \mu \mathrm{g}^{-1}$. The sgRNA was processed and purified as described in Leisen et al. (2020) using the primer sgRNA-MoAlb1. For the transformation, $120 \mu \mathrm{l}$ protoplast suspension with a concentration of $1.5^{*} 10^{8}$ protoplast $\mathrm{ml}^{-1}$ were mixed with $6 \mu \mathrm{g}$ donor DNA and the ribonucleoprotein (RNP) in a total volume of $60 \mu \mathrm{l}$ Tris- $\mathrm{CaCl}_{2}$ buffer. For RNP formation, $2 \mu \mathrm{g}$ of sgRNA were pre-incubated with $6 \mu \mathrm{g}$ Cas9SV40x4-enzyme for $1 \mathrm{~h}$ at $37^{\circ} \mathrm{C}$. For a non-directed integration, the resistance cassette was amplified with primer Fen-F and Fen-R (Table S1) and transformed without Cas9-enzyme. Thereafter, protoplasts were poured into $15 \mathrm{ml} \mathrm{CM}$ agar, containing 1.2 M sucrose for osmotic stabilisation. The next day, $20 \mathrm{ml}$ top agar were added containing fenhexamid (Bayer CropsScience, Monheim, Germany) in different concentrations and solved in DMSO. Mycelia grown through the top agar were transferred to new selection plates.

\section{Growth inhibition assays}

Commercially available fenhexamid was solved in DMSO and added at different concentrations to $\mathrm{CM}$ agar. A piece of mycelium from donor plates or conidia were transferred to these agar plates. Growth assays were performed at $25{ }^{\circ} \mathrm{C}$ in the dark for four to seven days. Colony area was quantified using the software ImageJ (Schneider et al., 2012). The concentration at which growth was inhibited by approximately $50 \%\left(\mathrm{EC}_{50}\right)$ in comparison to growth on plates without fenhexamid was determined graphically.

Verification of $\mathrm{Fen}^{R}$ integration and dermination of gene copy number

To analyze the integration site of the resistance cassette in the genome, genomic DNA of mutants was extracted as described in Leisen et al. (2020). Verification of $\mathrm{Fen}^{R}$ integration was done by PCR using primers Fen_F and Fen_R. For analysis of MoALB1 gene deletion mutants, primers binding to the border regions up- or downstream the integration site were used (MoALB1_F and MoALB1_R) and respective PCR products were sequenced to validate integration of the resistance gene into the $M o A L B 1$-locus.

Genomic DNA was used to determine the copy number of the $\mathrm{Fen}^{R}$-gene in an assay based on an study described in Solomon et al. (2008). For normalization of gene copy number, the single copy gene MoACTIN was selected as reference gene. qPCR was performed in technical triplicates with primers MoACTIN_F/MoACTIN_R and FfERG_F/ FfERG_R, at a concentration of $0.5 \mu \mathrm{M}$, for genes MoACTIN and FfERG27, respectively, in a CFX96 Touch Real-Time PCR Detection System (BioRad, Hercules, California, USA). For analysis, $5 \mu 1$ iTaq $^{\mathrm{TM}}$ Universal SYBR ${ }^{\circledR}$ Green Supermix (BioRad, Hercules, California, USA) were used according to the manufacturer's instruction. Serial dilutions of genomic DNA from a Fen ${ }^{\mathrm{R}}$ mutant $(50 \mathrm{ng}, 5 \mathrm{ng}, 0.5$ ng and 0.05 ng DNA in the reaction mixture) allowed to calculate the primer efficiencies for $\mathrm{E}_{\text {MoAKTIN }}=$ 2.002 and $\mathrm{E}_{F f E R G 27}=2.012$ using the equation $E$ $=10^{[-1 / \text { slope }]}$. By this, an amount of 0.5 to $5 \mathrm{ng}$ of genomic DNA was determined as optimal for each reaction in the qPCR. Further, we checked the primer efficiency of MoAKTIN and FfERG27 for each probe using $0.5 \mathrm{ng}$ and $5 \mathrm{ng}$ of genomic DNA in the reaction mixture. The following qPCR conditions were chosen: $95{ }^{\circ} \mathrm{C}$ for 3 minutes, 40 cycles of 3 seconds at $95^{\circ} \mathrm{C}$ and 30 seconds at $60{ }^{\circ} \mathrm{C}$.

To validate that this method can be used for determination of gene copy numbers, we first determined in a randomly selected $\mathrm{Fen}^{\mathrm{R}}$ mutant the relative ratio of MoACTIN to FfERG27 using the $\triangle$ ct-method and the equation Ratio $=2^{\operatorname{ct}(\text { MoAKTIN)-ct(FfERG27) }}$ (Livak \& Schmittgen, 2001). In this case the ratio was close to $1: 1$, indicating the presence of a single insertion of FfERG27 in the genome of this mutant. For calculation of our data we wanted to use the $\Delta \Delta$ ct-method (Pfaffl, 2001) which is more precise because the primer efficiencies of each probe is considered. The ratio was calculated using the equation

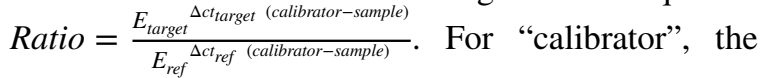
value for the previously mentioned $\mathrm{Fen}^{\mathrm{R}}$ mutant with a 1:1 ratio of the transcripts from MoACTIN and FfERG27 was selected. 


\section{Results}

Fenhexamid inhibits the growth of Magnaporthe oryzae

We tested whether M. oryzae isolate Guy11 was sensitive to fenhexamid. Therefore, mycelial growth, germination of conidia and regeneration of protoplasts were analyzed on CM agar supplemented with concentrations of fenhexamid in the range between 0.001 and $100 \mathrm{mg} \mathrm{l}^{-1}$ (Fig. 1). Inhibition of protoplast regeneration started at $1 \mathrm{mg} \mathrm{l}^{-1}$ fenhexamid and at 10-100 $\mathrm{mg} \mathrm{l}^{-1}$ no mycelial growth was observed (Fig. 1a). Similar inhibitory concentrations were determined for germination of conidia (Fig. 1b). Microscopy revealed that while at $1 \mathrm{mg} \mathrm{l}^{-1}$ fenhexamid conidia still germinated no germination was found at higher concentrations $\left(>10 \mathrm{mg} \mathrm{l}^{-1}\right.$ ). The same tendencies were observed for the inhibition of vegetative growth of mycelia (Fig. 1c). Therefore, 10-50 $\mathrm{mg} \mathrm{l}^{-1}$ fenhexamid were determined as an optimal concentration for distinction of fenhexamid resistant $\left(\mathrm{Fen}^{\mathrm{R}}\right)$ or sensitive $\left(\mathrm{Fen}^{\mathrm{S}}\right)$ M. oryzae genotypes.

Expression of FfERG27 leads to fenhexamid resistance of $M$. oryzae

To determine whether FfERG27 confers fenhexamid resistance in $M$. oryzae, a construct containing the FfERG27 expression cassette was amplified from

\section{concentration of fenhexamid}

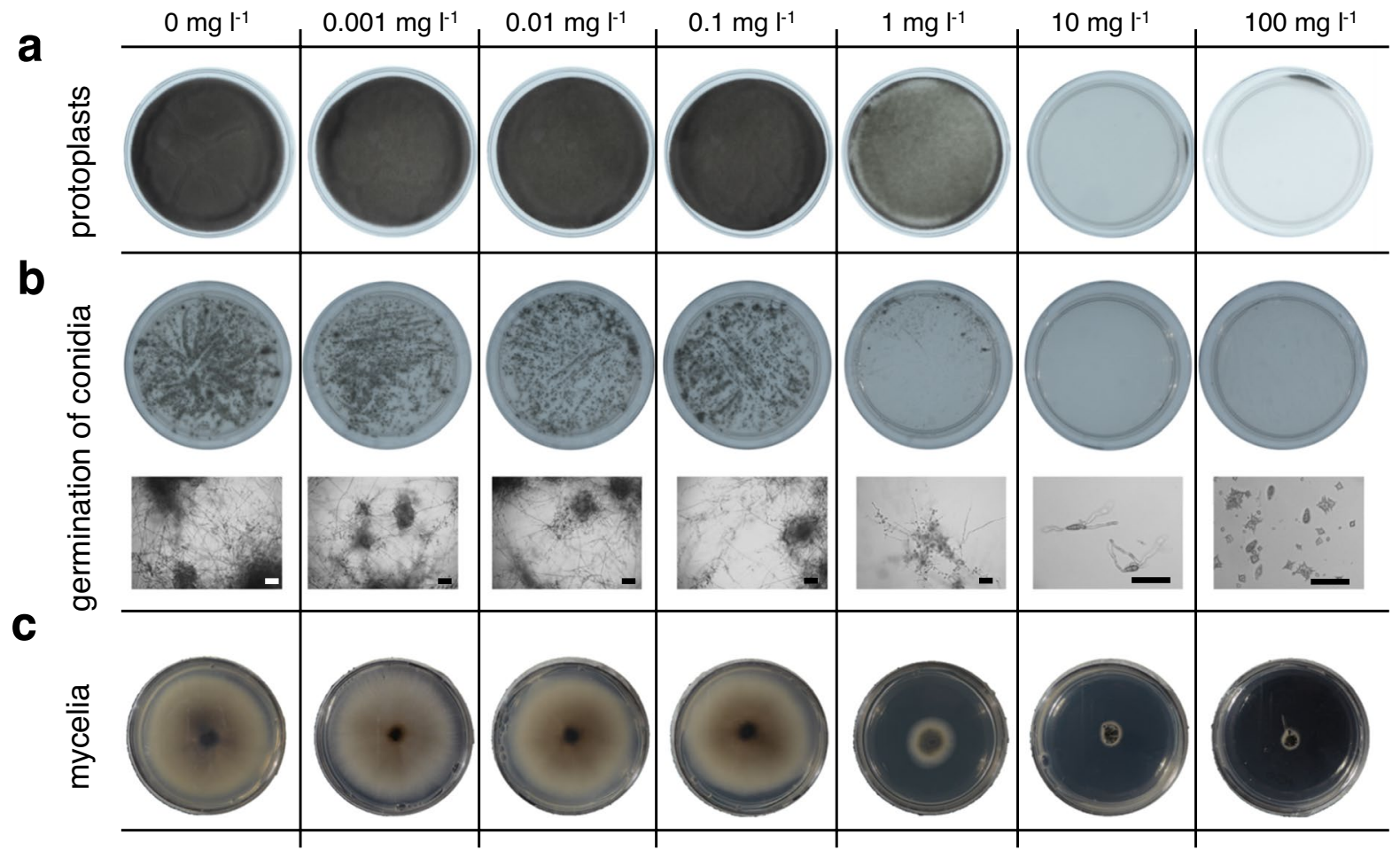

Fig. 1 Growth inhibition of M. oryzae Guy11 by fenhexamid. Concentrations of fenhexamid ranging from 0.001 to $100 \mathrm{mg} \mathrm{l}^{-1}$ were tested for an inhibitor effect on different $M$. oryzae structures. a Protoplasts of $M$. oryzae were poured in osmotic stabilized CM agar overlayed by a thin layer of $\mathrm{CM}$ agar supplemented with fenhexamid as indicated. Photographs were taken after six days. b A suspension with conidia (10000 conidia $\mathrm{ml}^{-1}$ ) was placed on agar plates containing fenhexa- mid. After four days, conidia were analyzed by microscopy for germination and formation of vegetative hyphae. Scale bars: $60 \mu \mathrm{m}$. c A piece of $M$. oryzae mycelium was placed on CM agar supplemented with different concentrations of fenhexamid and colony size was recorded after six days. Results shown are from a single experiment which was repeated with similar results 
the telomere vector pTEL-Fen (Fig. 2a). The purified PCR-product was introduced into $M$. oryzae Guy11 by protoplast transformation. In this way, we were able to generate $\mathrm{Fen}^{\mathrm{R}} M$. oryzae transformants $\left(M o F^{\mathrm{R}}{ }^{\mathrm{R}}\right)$ using a concentration of $30 \mathrm{mg} \mathrm{l}^{-1}$ fenhexamid in the top agar for selection (Fig. 2b). Transformation efficiency varied between 8 and 20 colonies per $\mu \mathrm{g}$ donor-DNA. $\mathrm{EC}_{50}$ values for sensitivity against fenhexamid were determined to increase from 1.5 to 8 $\mathrm{mg} \mathrm{l}^{-1}$ fenhexamid for the wild type and transformants with a single insertion of the resistance gene, respectively (Fig. 2c). Transformants with two insertions of the resistance gene showed an increased resistance level against the fungicide (Figure S1). Based on these results, and in agreement with data shown in Fig. 1, a concentration of $30 \mathrm{mg} \mathrm{l}^{-1}$ fenhexamid in the top-agar, at which wild type colonies did not grow, was used for selection in subsequent experiments.

Expression of FfERG27 does not alter growth and infection phenotype of $M$. oryzae

Next, we tested the versatility of the $\mathrm{Fen}^{R}$ marker gene (FfERG27) by investigating potential effects on vegetative growth under normal or stress conditions using the three aforementioned mutants with a single

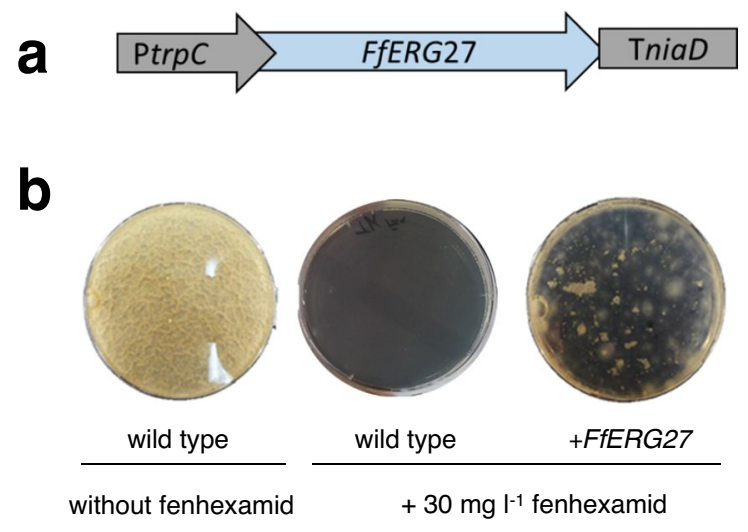

Fig. 2 Usage of fenhexamid for selection of $M$. oryzae transformants. a Schematic presentation of the FfERG27 $(F e n R)$ expression construct. b Pictures of M. oryzae colonies regenerated form wild type protoplasts on plates without or with fenhexamid (30 mg 1-1). Protoplasts transformed with the FfERG27 grew on fenhexamid selection media. Photographs were taken five days after sub-cultivation. c Comparison of mycelial growth of the wild type isolate $M$. oryzae Guy 11 $(M o W T)$ and three independently generated transformants insertion of the resistance gene. No differences were observed in growth on agar plates or formation of in vitro infection structures for the transformants compared to the wild type strain (Figure $3 a$ and b). Similarly, different $\mathrm{pH}$ and osmotic or oxidative stresses did not cause any growth alteration between the wild type strain and $M o F^{\mathrm{R}}{ }^{\mathrm{R}}$ mutants (Fig. 3c). Additionally, we tested the infection phenotype of $\mathrm{Fen}^{R}$ transformants on barley plants which, again, revealed no substantial differences in virulence compared to the wild type isolate (Fig. 4a-c).

Generation of gene deletion mutants by gene replacement

To ensure that the selection system can be used for generation of a targeted gene-deletion, fenhexamid resistant mutants of $M$. oryzae strain Guy 11 ku80 were generated using protoplast transformation as described in Leisen et al. (2020).

For this, the Cas9 endonuclease was pre-incubated with a sgRNA targeting MoALB1, a gene coding for a polyketide synthase which is involved in melanin biosynthesis. A deletion of this gene leads to whitish albino mutants (Foster et al., 2018). A co-transformation assay was done with a repair template containing

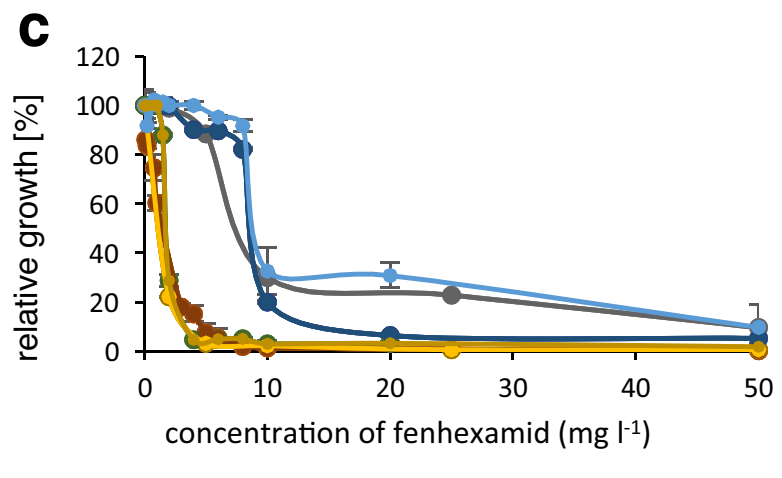

MoWT MoFen ${ }^{\mathrm{R}-1} \quad \mathrm{MoFen}^{\mathrm{R}-2} \bigcirc \mathrm{MoFen}^{\mathrm{R}-4}$

(MoFenR-1/-2/-4) with a single insertion of the resistance gene. Growth area on plates with different concentrations of fenhexamid was calculated relatively to those without the fungicide which were set to $100 \%$. Evaluation was done using the image processing software ImageJ. Data shown are based on three independently evaluated wild type and transformed genotypes, respectively, and error bars present the standard errors from three technical replicates for each isolate 
a
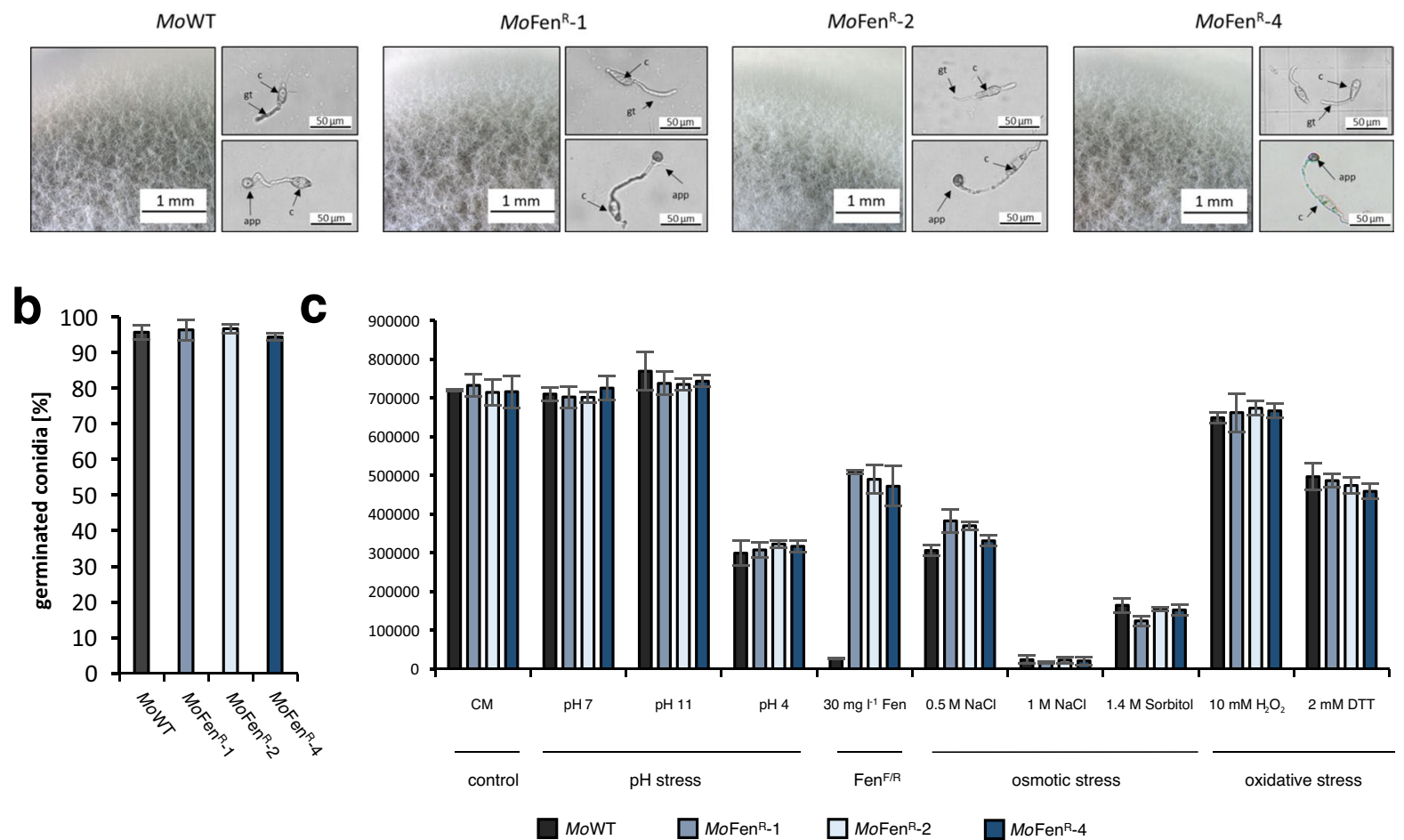

Fig. 3 Comparison of mycelial growth of $\operatorname{MoFen}^{\mathrm{R}}$ and MoWT isolates in response to different stimuli. a Growth of mycelium of MoWT and three fenhexamid resistant mutants $\left(M o F_{e n}{ }^{\mathrm{R}}-1, M o F_{e n}{ }^{\mathrm{R}}-2\right.$ and $\left.M o F_{e n}{ }^{\mathrm{R}}-4\right)$ on CM agar plates (left picture) and formation of in vitro infection structures on glass slides. Upper right picture taken at $14 \mathrm{~h}$ and lower picture at 24 h. c: conidia, gt: germ tube, app: appressoria. b Germination rate of conidia from the wild type isolate MoWT and of three fenhexamid resistant mutants after $24 \mathrm{~h}$ on glass slides. c Mycelium from $M o$ WT and $M o F^{\mathrm{R}}{ }^{\mathrm{R}}$ mutants was transferred to $\mathrm{CM}$ agar containing different additives to induce stress conditions. Different $\mathrm{pH}$ values of the media were adjusted with

homologous flanks to the genomic region of MoALB1 and the expression cassette for FfERG27 (Fig. 5a). Using a concentration of $30 \mathrm{mg} \mathrm{l}^{-1}$ fenhexamid for selection, as determined above, whitish transformants were observed (Fig. 5b). Randomly picked transformants were confirmed by PCR and sequencing to contain the $\mathrm{Fen}^{R}$ gene at the expected integration site in the MoALB1 locus (Fig. 5b, c). A qPCR assay for determination of gene copy numbers revealed that out of ten randomly selected transformants nine had a single insertion of the resistance gene, most likely by homologous recombination, while one had two
$\mathrm{NaOH}$ or HCL, $30 \mathrm{mg} \mathrm{l}^{-1}$ fenhexamid (Fen) was added to test for $\mathrm{Fen}^{\mathrm{R}}, 0.5 \mathrm{M}$ and $1 \mathrm{M} \mathrm{NaCl}$ and $1.4 \mathrm{M}$ Sorbitol were applied to change the osmotic potential and $10 \mathrm{mM} \mathrm{H}_{2} \mathrm{O}_{2}$ and $2 \mathrm{mM}$ DTT was added to generate oxidative stress. After five days photographs were taken to calculate the colony area using the software ImageJ. The experiment was performed three times. Columns represent the mean values and standard errors from three technical replicates of a representative experiment. No statistically significant differences could be found by Student's t-test $\left(\mathrm{p}<0.01, M o W T\right.$ vs. $\left.M o F^{\mathrm{R}}{ }^{\mathrm{R}}\right)$, except for the growth in presents of fenhexamid

insertions, the second of which probably is due to ectopic integration in the genome (Figure S1).

Distribution of $\mathrm{Fen}^{\mathrm{R}} / \mathrm{Fen}^{\mathrm{S}}$ in different Magnaporthe-isolates

Next, we tested whether the Fen ${ }^{\mathrm{R}}$ phenotype is similarly efficient for selection with additional isolates of the Magnaporthe-species complex. Different isolates were cultivated on agar containing $30 \mathrm{mg} \mathrm{l}^{-1}$ fenhexamid (Figure 6). Growth of Magnaporthe-isolates 70-15, BF17, BR116.5, BR29, BR32, CD180, Dsa1J, FR13, Guy11, H373, MoAR06, Mo33AR, TH16 und 


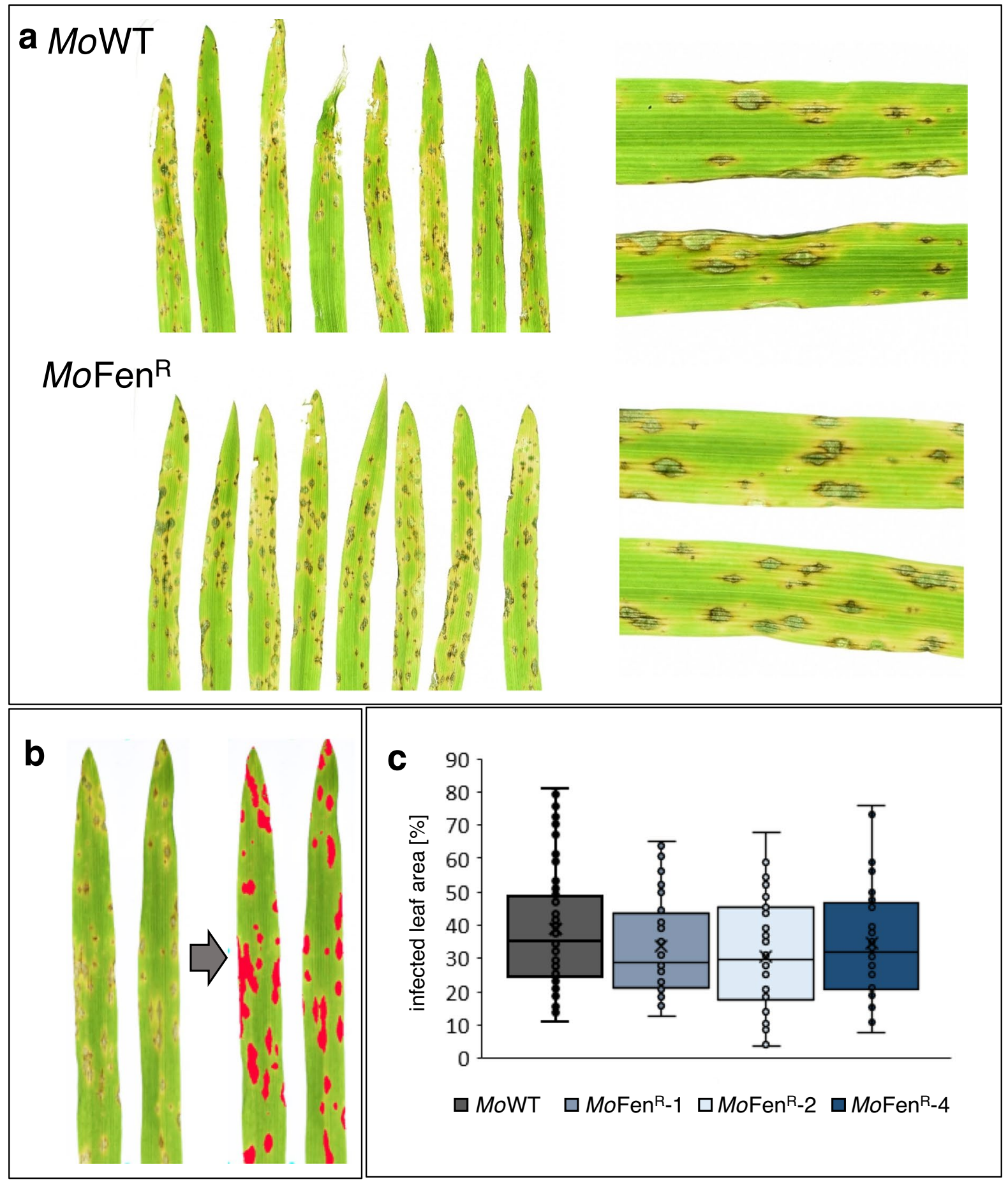

Fig. 4 Infection phenotype of $M o W T$ and $M o F e n{ }^{R}$ mutants on barley. Leaves of barley cultivar Ingrid were inoculated with the wild type $(M o W T)$ or transformants $\left(M o F^{\mathrm{R}}\right)$ and pictures were taken at seven days post inoculation (a). A magnification of disease symptoms is shown on the right side. The image based software Assess 2.0. was used to distinguish infected leaf area from green tissue as shown exemplarily in (b). Data generated this way were used for quantification of infected area per leaf (c). Data shown in the boxplot diagram are from 15 leaves for each genotype collected in three biological replicates. No statistically significant differences were found by Student's t-test between MoWT and each of the $M o F e{ }^{\mathrm{R}}$ mutants 

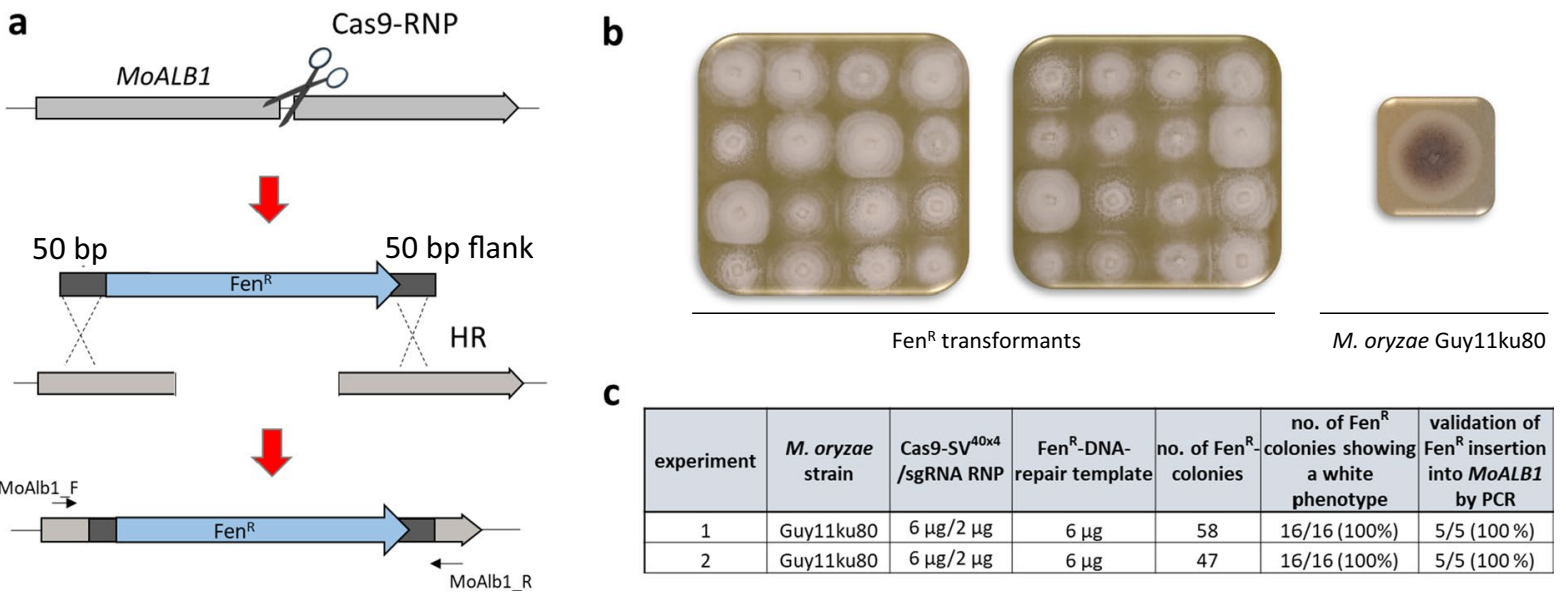

Fig. 5 Generation of Fen $^{\mathrm{R}} M o A L B 1$ gene deletion mutants by gene replacement. a Schematic illustration of the CRISPR/ Cas9 mediated gene replacement of MoALB1 by a fenhexamid resistance cassette $\left(\mathrm{Fen}^{R}\right)$ by homologous recombination. Positions of primers used for validation of the insertion of the repair template are shown. b 16 transformants were isolated from selection plates in each of two independent experiments which had a whitish mycelium in comparison to the wild type strain Guy11ku80. c Two independent experiments were performed to yield MoALB1 gene deletion mutants. Concentration of RNP and DNA-repair template are indicated. A total of 58 and 47 mutants were counted in the first and second experiment to be resistant to fenhexamid, respectively. From each experiment 16 of these transformants were further cultivated and all of them had a whitish mycelium. Randomly selected individuals (five for each experiment) were confirmed by PCR to contain the $\mathrm{Fen}^{R}$ gene. From these PCR-products, three were randomly selected and sequenced. This verified the expected insertion of the DNA-repair template at the MoALB1 locus by homologues recombination

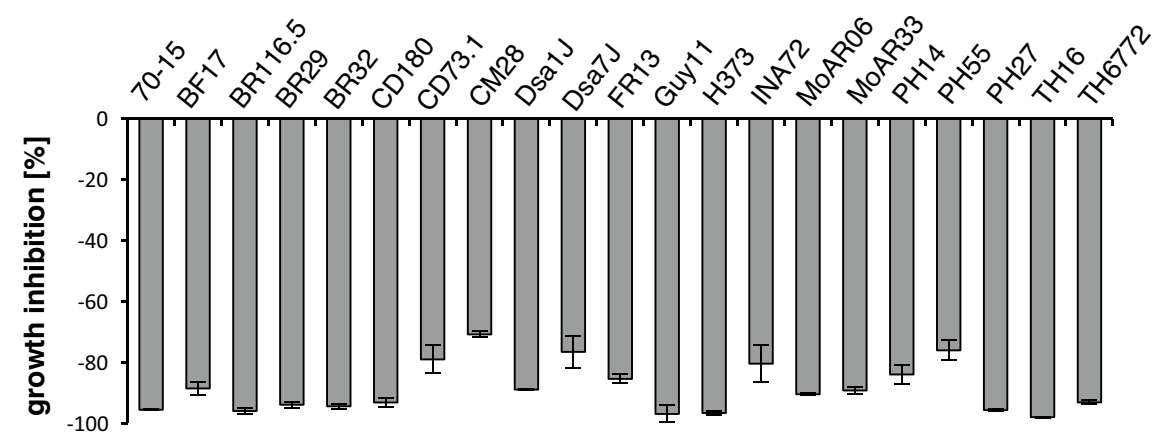

Fig. 6 Inhibition of mycelial growth by fenhexamid for different Magnaporthe-isolates. Growth assay with different Magnaporthe-isolates was performed in the presence of $30 \mathrm{mg}$ $\mathrm{l}^{-1}$ fenhexamid. Seven days after sub-culture photographs were taken and the colony area was calculated using the software

TH6772 were strongly inhibited with a reduction in growth area higher than $85 \%$ compared to their growth on agar without fenhexamid. Interestingly, isolates CD73.1, CM28, Dsa7J, INA 72 or PH55 seemed to be slightly less sensitive to fenhexamid with an inhibition of the mycelial growth less than $80 \%$ (Figure 6). To test whether this phenotype correlates
ImageJ. The growths inhibition rate for each isolate was calculated by comparing the growth area on media with or without fenhexamid. Results shown are the mean and standard error from a representative experiment with three replicates for each isolate. The experiment was repeated with similar results

with differences in the nucleotide sequences among ERG27 alleles, amplification from genomic DNA and sequencing was done for isolates CM28, PH14 and INA72. For comparison, sequences of Magnaportheisolates 70-15, Guy11, BR29, FR13, BR32, TH16 and CD156 were obtained from the Magnaporthe genome database GEMO (http://genome.jouy.inra. 
fr/gemo/). This revealed that deduced amino acid sequences of Erg27 were identical for isolates, except for BR29 which, instead, was highly similar to $\operatorname{Erg} 27$ of Pyricularia grisea strain NI907 (Figure S2). With respect to the different levels of sensitivity towards fenhexamid among the tested isolates, we conclude that other factors than the sequence of the ERG27 gene are also involved in modulation of sensitivity of $M$. oryzae against fenhexamid. This, in turn, underpins the need to test fenhexamid sensitivity for each wild type isolate for which fenhexamid will be used during selection of transformants.

\section{Discussion}

Fenhexamid in combination with the resistanceconferring gene FfERG27 of $F$. fujikuroi is wellestablished for selection of $B$. cinerea transformants (Cohrs et al., 2017). The fungicide can be used in its industrial formulation and is less expensive compared to commonly used antibiotics, such as e.g. hygromycin. M. oryzae isolate Guy11 is sensitive to fenhexamid with an $\mathrm{EC}_{50}$ value of $1.5 \mathrm{mg} \mathrm{l}^{-1}$ fenhexamid for growth of vegetative mycelium on artificial media (Figure 1). This is more than a magnitude higher compared to $B$. cinerea, for which about $0.1 \mathrm{mg} \mathrm{l}^{-1}$ is sufficient to inhibit mycelial growth by $50 \%\left(\mathrm{EC}_{50}\right)$ (Cohrs et al., 2017; Saito et al., 2014). We established that expression of a FfERG27 construct led to fenhexamid resistance in $M$. oryzae (Figure 2) as previously described for B. cinerea (Cohrs et al., 2017). While transformants were still able to grow at a concentration of $30 \mathrm{mg} \mathrm{l}^{-1}$ fenhexamid provided in the top agar, no "background" growth, e.g. caused by spontaneous mutations, were observed for the wild type (Figure 2). We further demonstrated that the FfERG27 resistance cassette can be efficiently used as repair template using homologous recombination in a CRISPR/Cas9 gene-deletion assay (Figure 5). The precision and efficiency was comparable to results obtained with the use of a hygromycin resistance cassette (Foster et al., 2018; Leisen et al., 2020).

As key requirement, a useful resistance marker should not affect the phenotype under investigation. For Fen ${ }^{\mathrm{R}}$ strains of $B$. cinerea $\left(\mathrm{HydR}^{+}\right)$a fitness penalty is reported and because ergosterols are involved in PAMP-triggered immunity an influence on pathogenicity cannot be excluded (Billard et al.,
2012; Billard et al., 2011; Rodrigues, 2018; Ziogas et al., 2003). M. oryzae $\mathrm{Fen}^{\mathrm{R}}$ transformants generated in this study, by contrast, were proved to be as virulent as the wild type strain on the host plant barley (Figure 4). Similarly, no differenced were observed between Fen $^{\mathrm{R}}$ transformants and the wild type isolate in response to different $\mathrm{pH}$ in the medium and osmotic or oxidative stresses (Figure 3). Based on these data, fenhexamid can be recommended without reservation for selection of $M$. oryzae transformants. However, a precautionary note has to be added because different $M$. oryzae isolates or species from the Magnaporthe-species complex differed in their sensitivity towards the fungicide (Figure 6). Notably, strains, such as Guy11 or 70-15, which still build the backbone for experimental use in laboratories, were more sensitive to fenhexamid than the more rarely used isolates CM28, Dsa1J and Ina72. Sequencing of these isolates or data mining in public depositories revealed, except for isolate BR29, identical MoErg27 sequences (Figure S2). Therefore, we concluded that the different degree of fenhexamid sensitivity among isolates must result from a yet unknown mechanism, such as e.g. different capabilities for detoxification or efflux carriers (Deising et al., 2008).

Taken together, we demonstrated that the use of fenhexamid in combination with the resistance-conferring gene $F f E r g 27$ represents an efficient selection system for transformants of $M$. oryzae. The availability of such novel selection markers is an important step forward to facilitate the generation of multiple gene deletions in M. oryzae.

Acknowledgments The Magnaporthe oryzae strains Guy11 and Guy11ku80 were kindly provided by D. Thareau (CIRAD, Montpellier, France). Further Magnaporthe-isolates were kindly provided by Y. Tosa (Kobe University, Japan), A. Perello (Universidad Nacional de La Plata, Argentinia) or obtained from the Faculty of Agriculture, Tamagawa University, Machida-shi, Japan. The plasmid pNDF-OCT, encoding the fenhexamid marker gene used in this study, was kindly made available by J. Schumacher (Westfälische Wilhelms-Universität Münster, Germany) to Matthias Hahn (Kaiserslautern University). Alan Slusarenko is kindly acknowledged for critical reading of the manuscript.

Availability of data and material The data supporting the findings of this study are available from the corresponding author upon reasonable request.

Author's contribution All authors have been personally involved in this study. Alex Wegner and Louisa Wirtz 
performed most of the experiments. Alex Wegner drafted the manuscript and interpreted the results. Thomas Leisen and Matthias Hahn were involved in the design of experiments and helped in interpretation of results. Ulrich Schaffrath designed experiments and finalized the manuscript. All co-authors red and approved the final version.

Funding Open Access funding enabled and organized by Projekt DEAL. Alex Wegner was funded by a RWTH Aachen University scholarships for Doctoral Students.

\section{Declarations}

Conflicts of interest The authors declare that they have no competing interests.

Ethical declarations The study does not involve any human participants and/or animals.

Open Access This article is licensed under a Creative Commons Attribution 4.0 International License, which permits use, sharing, adaptation, distribution and reproduction in any medium or format, as long as you give appropriate credit to the original author(s) and the source, provide a link to the Creative Commons licence, and indicate if changes were made. The images or other third party material in this article are included in the article's Creative Commons licence, unless indicated otherwise in a credit line to the material. If material is not included in the article's Creative Commons licence and your intended use is not permitted by statutory regulation or exceeds the permitted use, you will need to obtain permission directly from the copyright holder. To view a copy of this licence, visit http://creativecommons.org/licenses/by/4.0/.

\section{References}

Billard, A., Fillinger, S., Leroux, P., Bach, J., Lanen, C., Lachaise, H., Beffa, R., \& Debieu, D. (2011). Fenhexamid Resistance in the Botrytis Species Complex, Responsible for Grey Mould Disease. Fungicides - Beneficial and Harmful Aspects, 4, 61-78. https://doi.org/10.5772/27512

Billard, A., Fillinger, S., Leroux, P., Lachaise, H., Beffa, R., \& Debieu, D. (2012). Strong resistance to the fungicide fenhexamid entails a fitness cost in Botrytis cinerea, as shown by comparisons of isogenic strains. Pest Management Science, 68, 684-691. https://doi.org/10.1002/ps. 2312

Cohrs, K. C., Burbank, J., \& Schumacher, J. (2017). A new transformant selection system for the gray mold fungus Botrytis cinerea based on the expression of fenhexamidinsensitive ERG27 variants. Fungal genetics and biology, 100, 42-51. https://doi.org/10.1016/j.fgb.2017.02.001

Debieu, D., Bach, J., Hugon, M., Malosse, C., \& Leroux, P. (2001). The hydroxyanilide fenhexamid, a new sterol biosynthesis inhibitor fungicide efficient against the plant pathogenic fungus Botryotinia fuckeliana (Botrytis cinerea). Pest Management Science, 57, 1060-1067. https://doi.org/10.1002/ps.394
Debieu, D., Bach, J., Montesinos, E., Fillinger, S., \& Leroux, P. (2013). Role of sterol 3-ketoreductase sensitivity in susceptibility to the fungicide fenhexamid in Botrytis cinerea and other phytopathogenic fungi. Pest Management Science, 69, 642-651. https://doi.org/10.1002/ps.3418

Deising, H. B., Reimann, S., \& Pascholati, S. F. (2008). Mechanisms and significance of fungicide resistance. Brazilian Journal of Microbiology, 39, 286-295. https://doi.org/10. 1590/S1517-838220080002000017

Delventhal, R., Falter, C., Strugala, R., Zellerhoff, N., \& Schaffrath, U. (2014). Ectoparasitic growth of Magnaporthe on barley triggers expression of the putative barley wax biosynthesis gene CYP96B22 which is involved in penetration resistance. BMC Plant Biology, 14, 1471-2229. https://doi.org/10.1186/1471-2229-14-26

Fillinger, S., Leroux, P., Auclair, C., Barreau, C., Al Hajj, C., \& Debieu, D. (2008). Genetic analysis of fenhexamidresistant field isolates of the phytopathogenic fungus Botrytis cinerea. Antimicrobial agents and chemotherapy, 52, 3933-3940. https://doi.org/10.1128/AAC.00615-08

Foster, A. J., Martin-Urdiroz, M., Yan, X., Wright, H. S., Soanes, D. M., \& Talbot, N. J. (2018). CRISPR-Cas9 ribonucleoprotein-mediated co-editing and counterselection in the rice blast fungus. Scientific reports, 8, 1-12. https:// doi.org/10.1038/s41598-018-32702-w

Grabke, A., Fernández-Ortuño, D., \& Schnabel, G. (2013). Fenhexamid resistance in Botrytis cinerea from strawberry fields in the Carolinas is associated with four target gene mutations. Plant Disease, 97, 271-276. https://doi. org/10.1094/PDIS-06-12-0587-RE

Guo, M., Zhu, X., Li, H., Tan, L., \& Pan, Y. (2016). Development of a novel strategy for fungal transformation based on a mutant locus conferring carboxin-resistance in Magnaporthe oryzae. AMB Express, 6, 1-9. https://doi.org/10. 1186/s13568-016-0232-x

Jacob, S., Foster, A. J., Yemelin, A., \& Thines, E. (2015). High osmolarity glycerol (HOG) signalling in Magnaporthe oryzae: Identification of MoYPD1 and its role in osmoregulation, fungicide action, and pathogenicity. Fungal Biology, 119, 580-594. https://doi.org/10.1016/j.funbio.2015.03.003

Jeong, J. S., Mitchell, T. K., \& Dean, R. A. (2007). The Magnaporthe grisea snodprot1 homolog, MSP1, is required for virulence. FEMS Microbiology Letter, 273, 157-165. https://doi.org/10.1111/j.1574-6968.2007.00796.x

Kachroo, P., Potnis, A., \& Chattoo, B. B. (1997). Transformation of the rice blast fungus Magnaporthe grisea to benomyl resistance. World Journal of Microbiology \& Biotechnology, 13, 185-187. https://doi.org/10.1023/A:10185 89714357

Leisen, T., Bietz, F., Werner, J., Wegner, A., Schaffrath, U., Scheuring, D., Willmund, F., Mosbach, A., Scalliet, G., \& Hahn, M. (2020). CRISPR/Cas with ribonucleoprotein complexes and transiently selected telomere vectors allows highly efficient marker-free and multiple genome editing in Botrytis cinerea. PLoS Pathogens, 16, e1008326. https://doi.org/10.1371/journal.ppat.1008326

Leung, H., Lehtinen, U., Karjalainen, R., Skinner, D., Tooley, P., Leong, S., \& Ellingboe, A. (1990). Transformation of the rice blast fungus Magnaporthe grisea to hygromycin 
B resistance. Current Genetics, 17, 409-411. https://doi. org/10.1007/BF00334519

Livak, K. J., \& Schmittgen, T. D. (2001). Analysis of relative gene expression data using real-time quantitative PCR and the 2- $\Delta \Delta \mathrm{CT}$ method. Methods, 25, 402-408. https://doi. org/10.1006/meth.2001.1262

Martinez, S.I., Wegner, A., Bohnert, S., Schaffrath, U., Perelló, A. (2021). Tracing seed to seedling transmission of the wheat blast pathogen Magnaporthe oryzae pathotype Triticum. Plant Pathology, 1-10. https://doi.org/10.1111/ ppa. 13400

Pfaffl, M. W. (2001). A new mathematical model for relative quantification in real-time RT-PCR. Oxford University Press, 29, 16-21. https://doi.org/10.1093/nar/29.9.e45

Portz, K., Casanova, F., Jordine, A., Bohnert, S., Mehl, A., Portz, D., \& Schaffrath, U. (2021). Wheat blast caused by Magnaporthe oryzae pathovar Triticum is efficiently controlled by the plant defence inducer isotianil. Journal of Plant Diseases and Protection, 128, 249-259. https://doi. org/10.1007/s41348-020-00378-y

Rodrigues, M. L. (2018). The Multifunctional Fungal Ergosterol. MBio, 9, e01755-e01718. https://doi.org/10.1128/ mBio.01755-18

Saito, S., Cadle-Davidson, L., \& Wilcox, W. F. (2014). Selection, fitness, and control of grape isolates of Botrytis cinerea variably sensitive to fenhexamid.
Plant Disease, 98, 233-240. https://doi.org/10.1094/ PDIS-07-13-0746-RE

Schneider, C., Rasband, W., \& Eliceiri, K. (2012). NIH Image to ImageJ: 25 years of image analysis. Nature methods, 9, 671-675. https://doi.org/10.1038/nmeth.2089

Solomon, P. S., Ipcho, S. V. S., Hane, J. K., Tan, K. C., \& Oliver, R. P. (2008). A quantitative PCR approach to determine gene copy number. Fungal Genetics Reports, 55, 5-8. https://doi.org/10.4148/1941-4765.1082

Talbot, N. J., Ebbole, D. J., \& Hamer, J. E. (1993). Identification and characterization of MPG1, a gene involved in pathogenicity from the rice blast fungus Magnaporthe grisea. Plant Cell, 5, 1575-1590. https://doi.org/10.1105/ tpc.5.11.1575

Zhang, L., Zhang, D., Chen, Y., Ye, W., Lin, Q., Lu, G., Ebbole, D.J., Olsson, S., Wang, Z. (2019). Magnaporthe oryzae CK2 Accumulates in Nuclei, Nucleoli, at Septal Pores and Forms a Large Ring Structure in Appressoria, and Is Involved in Rice Blast Pathogenesis. Frontiers in cellular and infection microbiology, 9, 1-12. https://doi. org/10.3389/fcimb.2019.00113

Ziogas, B. N., Markoglou, A. N., \& Malandrakis, A. A. (2003). Studies on the inherent resistance risk to fenhexamid in Botrytis cinerea. European Journal of Plant Pathology, 109, 311-317. https://doi.org/10.1023/A:1023522213675 